\title{
Frequency of Social Isolation and Homeboundness and Their Relationships with High-Level Functional Capacity in Elderly Diabetic Patients
}

This article was published in the following Dove Press journal: Clinical Interventions in Aging

\section{Satoshi Ida \\ Ryutaro Kaneko \\ Kanako Imataka $\mathbb{D}$ \\ Kaoru Okubo \\ Yoshitaka Shirakura \\ Kentaro Azuma \\ Ryoko Fujiwara (D) \\ Hiroka Takahashi \\ Kazuya Murata}

Department of Diabetes and Metabolism, Ise Red Cross Hospital, Ise-shi, Mie 516$85 / 2$, Japan
Correspondence: Satoshi Ida Department of Diabetes and Metabolism, Ise Red Cross Hospital, I-47|-2, Funae, I-Chome, Ise-shi, Mie 5I6-85I2, Japan Tel +8I 596-28-2I7I

Fax +8I 596-28-2965

Email bboy98762006@yahoo.co.jp
Purpose: To determine the frequency of social isolation (hereinafter, isolation) and homeboundness in elderly diabetic patients and to investigate their relationships with high-level functional capacity.

Patients and Methods: Subjects were diabetic outpatients aged 65 years and older who were visiting the Japanese Red Cross Ise Hospital. Tokyo Metropolitan Institute of Gerontology Index of Competence (TMIG-IC) was used to evaluate high-level functional capacity. Isolation was defined as having less than one interaction per week with someone other than co-habiting family members. Homeboundness was defined as leaving the house less than once a day. Multiple regression analysis was performed with the TMIG-IC score as the dependent variable and isolation and homeboundness as independent variables.

Results: Four hundred fifty-one patients were included in the analysis. The frequency of isolation and homeboundness affected $37 \%$ and $13.3 \%$ of men and $28.9 \%$ and $20.6 \%$ of women, respectively. The adjusted partial regression coefficient of the TMIG-IC scores of isolated, homebound, and isolated+homebound men was -0.94 [95\% confidence interval $(\mathrm{CI}),-1.68$ to $-0.21 ; \mathrm{P}=$ 0.012 ], -0.27 (95\% CI, -1.93 to $1.39 ; \mathrm{P}=0.746)$, and $-4.03(95 \% \mathrm{CI},-5.37$ to $-2.68 ; \mathrm{P}<0.001)$ in relation to that of the non-isolated and non-homebound group as reference. In women, the respective coefficients to the reference were -1.33 (95\% $\mathrm{CI},-2.93$ to $0.25 ; \mathrm{P}=0.099),-0.65$ (95\% CI, -2.56 to $1.26 ; \mathrm{P}=0.501)$, and $-3.01(95 \% \mathrm{CI},-4.92$ to $-1.1 ; \mathrm{P}=0.002)$, respectively.

Conclusion: The frequency of isolation was high in both female and male elderly diabetic patients. In men, there was a significant relationship between isolation and decline in highlevel functional capacity. In both men and women, there was a significant relationship between isolation+homeboundness and decline in high-level functional capacity.

Keywords: community-dwelling elderly, Tokyo Metropolitan Institute of Gerontology Index of Competence, TMIG-IC, diabetes in the elderly, activities of daily living

\section{Introduction}

As the number of elderly individuals is on the rise, lowered activities of daily living (ADL) and decreased physical and mental function in the elderly are recognized as problems. $^{1,2}$ Lawton and Brody ${ }^{3}$ proposed a seven-stage hierarchical model to assess the functionality in the elderly from simple to more complex functions, from survival, functional health, perception, cognition, physical independence, instrumental ADL (IADL), ability to handle a situation, and social roles. ADL comprises various levels, such as basic ADL, more complex activities (IADL), and high-level functional capacity, including intellectual activity, intellectual ability, and submit your manuscript DovePress in 口 
social roles. Among these subtypes of ADL, the first one is decline in high-level functional capacity, ${ }^{3}$ and this is connected with decline in cognitive function, ${ }^{4}$ stroke, ${ }^{5}$ increased medical costs, ${ }^{5}$ and death. ${ }^{6}$ It is understood that diabetic patients are at a higher risk of decline in ADL, including high-level functional capacity, compared with non-diabetics; ${ }^{7}$ thus, high-level functional capacity is an important clinical outcome of elderly diabetic patients.

Another important problem associated with the aging population is social vulnerability, that is, isolation and homeboundness. Isolation is associated with decreased cognitive function, ${ }^{8}$ long-term care, ${ }^{8}$ and death,,${ }^{9,10}$ and homeboundness is associated with decreased physical function and walking disabilities ${ }^{11}$ and hospitalization. ${ }^{12}$ Although operative definitions of these terms vary from study to study, the reported incidences of social isolation and homeboundness in the elderly are $7-17 \%{ }^{13}$ and $5.6 \%,{ }^{14}$ respectively. Fujiwara et al ${ }^{15}$ defined social isolation as having less than one interaction with others per week, regardless of whether the interaction is in person or not, and homeboundness as leaving the house less than once a day. They surveyed these parameters in community-dwelling elderly and found that the incidences of social isolation and homeboundness were $34.4 \%$ and $22.9 \%$ for men and $15.6 \%$ and $32.9 \%$ for women, respectively, and that these parameters were associated with decline in high-level functional capacity. ${ }^{15}$ Isolation and homeboundness are extremely important challenges given their negative impact on decline in high-level functional capacity, which can lead to loss of independence requiring long-term care and eventually to death. As mentioned above, although studies on community-dwelling elderly have investigated the relationships between frequency of isolation and homeboundness and high-level functional capacity, ${ }^{11,15}$ there are no studies on this topic that focused exclusively on elderly diabetic patients. Diabetic patients are characterized by higher rates of vascular complications and frailty than non-diabetic patients. ${ }^{16,17}$ Therefore, we deemed it clinically important to determine the incidences of social isolation and homeboundness in elderly diabetes patients and to compare these incidences based on sex to investigate their impacts on high-level functional capacity. The present study thus aimed to investigate the incidences of social isolation and homeboundness in elderly diabetic patients and to study their relationships with high-level functional capacity according to the patients' sex.

\section{Patients and Methods}

\section{Study Design and Subjects}

This study is a cross-sectional study on diabetic patients visiting the Japanese Red Cross Ise Hospital (Ise City, Mie Prefecture, Japan) on an outpatient basis. It was conducted by obtaining written informed consent of the participants and approval of the Ethical Review Board of the Japanese Red Cross Ise Hospital. Eligibility criteria were diabetic patients of 65 years and above who visited the Japanese Red Cross Ise Hospital between June 2017 and August 2019 on an outpatient basis. Exclusion criteria were patients with current or previously diagnosed alcoholism, severe psychiatric diseases, and malignant tumors, patients with an implanted pacemaker, patients with bilateral knee or hip joint replacement, patients with home oxygen therapy, patients diagnosed with heart failure within 6 months, and patients who could not cooperate in the survey without assistance.

\section{Evaluation of High-Level Functional Capacity}

We used the Tokyo Metropolitan Institute of Gerontology Index of Competence (TMIG-IC), a self-administered survey, to evaluate high-level functional capacity. ${ }^{18}$ The TMIG-IC is widely used to evaluate high-level functional capacity in Japan and its reliability and validity have been verified. ${ }^{18}$ It comprises 13 items in total, with 5 items on IADL such as preparing meals, managing personal finances, and using public transportation; 4 items on effectance; and 4 items on social roles (Japan Geriatrics Society website, https://www.jpn-geriat-soc.or.jp/tool/pdf/tool 08 . pdf). The questionnaire is answered binarily with a yes or no. Total scores range between 0 and 13, with higher scores indicating higher high-level functional capacity.

\section{Evaluation of Isolation and Homeboundness}

We defined the terms "isolation" and "homeboundness" based on the definitions provided by Fujiwara et $\mathrm{al}^{15}$. This definition uses questions on in-person social contact ("How often do you see or go out with friends, neighbors, and family members who do not live at your dwelling?") and remote contact ("How often do you exchange calls or letters with friends, neighbors, and family members who do not live at your dwelling?") to which respondents select "Less than once a week" or "Once a week or more". For both questions, those who selected "Less than once 
a week" were defined as isolated. With regards to the question on outings, respondents answered the question "How many times a day do you leave your house?" with either of the following responses: "Less than once a week" or "At least once a day". Those who answered "Less than once a week" were defined as homebound.

\section{Assessment of Other Variables}

Age, sex, body mass index [BMI; weight (kg)/height (m2)], smoking habit, drinking habits, type of diabetes (1, 2, or other), diabetes disease duration, hemoglobin A1c (HbA1c), hypertension, dyslipidemia, diabetic retinopathy, neuropathy or nephropathy, cardiovascular disease, use of oral hypoglycemic drugs, sarcopenia, cognitive function, depression, and whether respondents lived alone were determined. Diabetes types were classified into types 1,2, and other according to the diagnostic criteria of the Japanese Diabetes Society, ${ }^{19}$ systolic and diastolic blood pressure (BP) were measured in the examination room. Hypertension was defined as the presence of one or more of the following conditions: systolic $\mathrm{BP} \geqq 130 \mathrm{mmHg}$, diastolic BP $\geqq 80 \mathrm{mmHg}$, or use of hypotensive medication. With regards to lipid levels, dyslipidemia was defined as the presence of one or more of the following conditions: triglycerides $\geqq 150 \mathrm{mg} / \mathrm{dl}$, high-density lipoprotein-cholesterol $<40 \mathrm{mg} / \mathrm{dl}$, low-density lipoprotein-cholesterol (LDLC) $\geqq 120 \mathrm{mg} / \mathrm{dl}$ (LDLC $\geqq 100 \mathrm{mg} / \mathrm{dl}$ in the presence of coronary artery disease), or use of hypolipidemic medication. Diabetic retinopathy was defined as a diagnosis of the disease by an ophthalmologist. Diabetic neuropathy was defined as the presence of decreased Achilles tendon reflex, decreased sensitivity to vibration applied to the lateral malleolus, or abnormal results to nerve conduction studies. Cardiovascular disease was defined as current or previous history of ischemic heart diseases, such as angina pectoris and myocardial infarction, or neurovascular diseases, such as cerebral infarction. Sarcopenia was assessed by the Japanese version of the SARC-F, ${ }^{20}$ a fiveitem self-administered questionnaire that examines strength, assistance in walking, rising from a chair, climbing stairs, and falls. Respondents choose one from "None," "Some," or "A lot, or unable" that best describes their level of difficulty to perform the action, with the exception of the item for falls, which is answered by choosing one from "None," "1 to 3 falls," or " 4 or more falls" that are assigned 0,1 , and 2 points, respectively. Total scores range between 0 and 10 points, and a score of 4 or above is defined as sarcopenia. The Japanese version of the Test Your Memory (TYM-J) questionnaire is a self-administered tool that evaluates cognitive function adapted by Hanyu et $\mathrm{al}^{21}$ with tested validity. The tasks are orientation (10 points), ability to copy a sentence ( 2 points), semantic knowledge ( 3 points), calculation ( 4 points), verbal fluency (4 points), similarities (4 points), naming (5 points), visuospatial abilities ( 2 tasks, a total of 7 points), recalling a copied sentence ( 6 points), and ability to do the test ( 5 points). Total points range between 0 and 50 points, with lower scores indicating lower cognitive function. Based on this report, we defined TYM-J total scores of 44 points and lower as the presence of cognitive impairment. The nine-item Japanese version of the Patient Health Questionnaire 9 (J-PHQ-9) adapted by Muramatsu et $\mathrm{al}^{22}$ with verified validity was used to measure depression, which is answered on a 4-point Likert scale on symptoms over the preceding 2 weeks: (almost every day, 3 points; more than half, 2 points; several days, 1 point; never, 0 point). Total scores range between 0 and 27 points, with higher scores indicating higher degrees of depression. As per this previous study, we defined depression as J-PHQ-9 scores of 5 and higher.

\section{Statistical Analysis}

Patient background was organized into non-isolation+nonhomeboundness, isolation, homeboundness, and isolation thomeboundness categories. Continuous variables were analyzed by analysis of variance (multiple comparisons by the Bonferroni method), and binary variables were compared using chi-square test. We calculated the adjusted partial regression coefficients related to high-level functional capacity of isolation and homeboundness in a multiple regression analysis with TMIG-IC scores as the dependent variable and the four categories of isolation and homeboundness (compared with the non-isolated and non-homebound group as reference) as the independent and adjustment variables. We determined the variables to be studied based on clinical judgment and with reference to previous studies: ${ }^{11,15}$ age, BMI, HbAlc, number of comorbidities (hypertension, dyslipidemia, diabetic retinopathy, diabetic neuropathy, diabetic nephropathy, and cardiovascular disease), sarcopenia, cognitive impairment, depression, and living alone. Two-sided significance levels ( $\mathrm{P}<0.05)$ were considered to be statistically significant, and Stata version 16.0 (Stata Corporation LP, College Station, TX) was used for statistical analysis.

\section{Results}

There were 504 patients who met the eligibility criteria. Fifty-three of these patients with missing data were excluded. The remaining 451 patients (257 men, 194 women) were included in the analysis. Compared to 
these 451 patients, the 53 excluded patients had lower TMIG scores and higher incidences of depression and social isolation. The backgrounds of these patients are displayed in Tables 1 and 2. There were 152 men (59.1\%) who were neither isolated nor homebound, 71 men $(27.6 \%)$ who were isolated, 10 men who were homebound (3.9\%), and 24 men who were both isolated and homebound $(9.4 \%)$. There were 118 women who were neither isolated nor homebound $(60.8 \%), 36$ women who were isolated (18.6\%), 20 women who were homebound $(10.3 \%)$, and 20 women who were both isolated and homebound (10.3\%). Among men, those who were both isolated and homebound had the highest age, highest frequency of sarcopenia, and lowest TMIG-IC scores. In women, those who were isolated, homebound, and both isolated and homebound had higher rates of cardiovascular disease, sarcopenia, and depression than their neither isolated nor homebound counterparts. Furthermore, similar to men, women who were isolated+homebound had significantly lower TMIG-IC scores than the other groups.
The results of multiple regression analysis are shown in Table 3. In men, the adjusted partial regression coefficient of the TMIG-IC scores of the isolated, homebound, and isolated+homebound groups relative to that of the neither isolated nor homebound group were -0.94 [95\% confidence interval $(\mathrm{CI}),-1.68$ to $-0.21 ; \mathrm{P}=0.012],-0.27$ (95\% CI, -1.93 to $1.39 ; \mathrm{P}=0.746)$, and -4.03 (95\% CI, -5.37 to $-2.68 ; \mathrm{P}<0.001)$, respectively. In women, the adjusted partial regression coefficient of the TMIG-IC scores of the isolated, homebound, and isolated+homebound groups relative to that of the neither isolated nor homebound group were $-1.33(95 \% \mathrm{CI},-2.93$ to 0.25 ; $\mathrm{P}=$ $0.099),-0.65(95 \% \mathrm{CI},-2.56$ to $1.26 ; \mathrm{P}=0.501)$, and $-3.01(95 \% \mathrm{CI},-4.92$ to $-1.1 ; \mathrm{P}=0.002)$, respectively.

\section{Discussion}

According to Fujiwara et $\mathrm{al}^{15}$ who used the same definitions of isolation and homeboundness as in our study to analyze community-dwelling elderly, the frequency of isolation and homeboundness were $34.4 \%$ and $22.9 \%$ in men

Table I Characteristics of the Analysis Population in Men

\begin{tabular}{|c|c|c|c|c|}
\hline & $\begin{array}{l}\text { Non-Isolation/Non- } \\
\text { Homebound }\end{array}$ & $\begin{array}{l}\text { Isolation } \\
\text { Alone }\end{array}$ & $\begin{array}{l}\text { Homebound } \\
\text { Alone }\end{array}$ & $\begin{array}{l}\text { Isolation/ } \\
\text { Homebound }\end{array}$ \\
\hline & $n=152(59.1 \%)$ & $n=7 \mid(27.6 \%)$ & $n=10(3.9 \%)$ & $n=24(9.4 \%)$ \\
\hline Age (years), mean (SD) & $72.3(5.3)^{d}$ & $73.1(4.8)^{d}$ & $72(6.1)^{d}$ & $77.8(6.4)^{\mathrm{a}, \mathrm{b}, \mathrm{c}}$ \\
\hline BMI $\left(\mathrm{kg} / \mathrm{m}^{2}\right)$, mean $(\mathrm{SD})$ & $24.4(4.9)$ & $24.3(4.3)$ & $25.5(3.1)$ & $23.3(4.1)$ \\
\hline TIDM/T2DM, \% & $4.7 / 95.3$ & $2.2 / 97.8$ & $14.2 / 85.9$ & $8.3 / 91.7$ \\
\hline HbAlc (\%), mean (SD) & $7.4(1.2)$ & $6.9(0.7)$ & $7.5(1.2)$ & $7.3(0.7)$ \\
\hline $\begin{array}{l}\text { Duration of diabetes (years), mean } \\
\text { (SD) }\end{array}$ & $18.1(11)$ & $18.8(11)$ & I $3.8(8.1)$ & $25.5(14.1)$ \\
\hline Alcohol consumption, \% & 26.1 & 30.5 & 33.3 & II.I \\
\hline Smoking, \% & 37.9 & 41.6 & 33.3 & II.I \\
\hline Hypertension, \% & 80.7 & 84.4 & 71.4 & 83.3 \\
\hline Dyslipidemia, \% & 75.2 & 64.4 & 85.7 & 75 \\
\hline Retinopathy, \% & 39.3 & 46.3 & 66.6 & 33.3 \\
\hline Neuropathy, \% & 60.3 & 71.8 & 80 & 87.5 \\
\hline Nephropathy, \% & 58.1 & 61.3 & 50 & 91.6 \\
\hline Cardiovascular disease, \% & 32.3 & 32.5 & 42.8 & 33.3 \\
\hline Sarcopenia, \% & $9.2^{\mathrm{c}, \mathrm{d}}$ & 10 & $40^{\mathrm{a}}$ & $50^{\mathrm{a}}$ \\
\hline Depression, \% & 40.1 & 51.1 & 42.8 & 50 \\
\hline Cognitive impairment, \% & 15.7 & 15.4 & 30 & 12.5 \\
\hline Living alone, $\%$ & 10.7 & $21.1^{d}$ & $20^{d}$ & $0^{\mathrm{b}, \mathrm{c}}$ \\
\hline Oral hypoglycemic agents, \% & 78 & 80 & 85.7 & 50 \\
\hline GLP-I analog, \% & $8.5^{c}$ & $8.8^{\mathrm{c}}$ & $42.8^{\mathrm{a}, \mathrm{b}, \mathrm{d}}$ & $0^{c}$ \\
\hline Insulin, \% & $62.5^{\mathrm{c}, \mathrm{d}}$ & 64.4 & $100^{\mathrm{a}}$ & $91.6^{\mathrm{a}}$ \\
\hline TMIG-IC (points), mean (SD) & $\mathrm{II} .7(\mathrm{I} .8)^{\mathrm{b}, \mathrm{c}, \mathrm{d}}$ & $10.3(2.6)^{\mathrm{a}, \mathrm{c}}$ & $9.6(3.7)^{a, b, d}$ & $6.8(3.4)^{\mathrm{a}, \mathrm{c}}$ \\
\hline
\end{tabular}

Notes: ${ }^{a}$ Significantly different from Non-isolation/Non-homebound. 'Significantly different from Isolation Alone. 'Significantly different from Homebound Alone. dSignificantly different from Isolation/Homebound.

Abbreviations: SD, standard deviation; BMI, body mass index; TIDM/T2DM, type I/type 2 diabetes mellitus; HbAIc, hemoglobin AIc; GLP-I, glucagon-like peptide-I; TMIG-IC, Tokyo Metropolitan Institute of Gerontology Index of Competence. 
Table 2 Characteristics of the Analysis Population in Women

\begin{tabular}{|c|c|c|c|c|}
\hline & $\begin{array}{l}\text { Non-Isolation/Non- } \\
\text { Homebound }\end{array}$ & $\begin{array}{l}\text { Isolation } \\
\text { Alone }\end{array}$ & $\begin{array}{l}\text { Homebound } \\
\text { Alone }\end{array}$ & $\begin{array}{l}\text { Isolation/ } \\
\text { Homebound }\end{array}$ \\
\hline & $n=118(60.8 \%)$ & $n=36(18.6 \%)$ & $n=20(10.3 \%)$ & $n=20(10.3 \%)$ \\
\hline Age (years), mean (SD) & $72.5(5.3)^{c}$ & $72(6)^{c}$ & $76.4(5.6)^{a, b}$ & $74.2(7.1)$ \\
\hline BMI $\left(\mathrm{kg} / \mathrm{m}^{2}\right)$, mean $(\mathrm{SD})$ & $24.1(4.8)$ & $23.4(4.6)$ & $25.5(5.2)$ & 24.9 (3.9) \\
\hline TIDM/T2DM/other, \% & $10.2 / 89.8$ & $16.6 / 83.4$ & $0 / 100$ & $6.6 / 93.4$ \\
\hline HbAlc (\%), mean (SD) & $7.3(I)$ & $7.2(0.7)$ & $7.8(1)$ & $7.6(1.3)$ \\
\hline $\begin{array}{l}\text { Duration of diabetes (years), mean } \\
\text { (SD) }\end{array}$ & $16.6(11.7)$ & $21.6(9.2)$ & $23.4(8.5)$ & $21.2(9.7)$ \\
\hline Alcohol consumption, \% & 5.7 & 0 & 0 & 18.1 \\
\hline Smoking, \% & 3.7 & 16.6 & 0 & 18.1 \\
\hline Hypertension, \% & 66.1 & 83.3 & 84.6 & 93.3 \\
\hline Dyslipidemia, \% & 64 & 77.7 & 84.6 & 93.3 \\
\hline Retinopathy, \% & 45.9 & 61.1 & 61.5 & 35.7 \\
\hline Neuropathy, \% & 66.6 & 75 & 90 & 91.6 \\
\hline Nephropathy, \% & 49.1 & 61.1 & 41.6 & 60 \\
\hline Cardiovascular disease, \% & $7.6^{b, c, d}$ & $23.5^{\mathrm{a}}$ & $58.3^{\mathrm{a}}$ & $33.3^{\mathrm{a}}$ \\
\hline Sarcopenia, \% & $16.2^{\mathrm{c}, \mathrm{d}}$ & $19.4^{c, d}$ & $60^{\mathrm{a}, \mathrm{b}}$ & $70^{\mathrm{a}, \mathrm{b}}$ \\
\hline Depression, \% & $34.7^{b, c, d}$ & $55^{\mathrm{a}}$ & $64.2^{\mathrm{a}}$ & $86.6^{\mathrm{a}}$ \\
\hline Cognitive impairment, \% & 16.9 & 5.5 & 30 & 25 \\
\hline Living alone, $\%$ & 17.2 & 16.6 & 30 & 35 \\
\hline Oral hypoglycemic agents, \% & 75 & 88.8 & 84.6 & 73.3 \\
\hline GLP-I analog, \% & 14.7 & 22.2 & 23 & 6.6 \\
\hline Insulin, \% & 63.2 & 77.7 & 92.3 & 80 \\
\hline TMIG-IC (points), mean (SD) & II.8 $(2.2)^{\mathrm{b}, \mathrm{d}}$ & $10.4(3.1)^{\mathrm{a}, \mathrm{d}}$ & $10.3(2.7)^{d}$ & $8.0(3.4)^{\mathrm{a}, \mathrm{b}, \mathrm{c}}$ \\
\hline
\end{tabular}

Notes: ${ }^{a}$ Significantly different from Non-isolation/Non-homebound. ${ }^{b}$ Significantly different from Isolation Alone. 'Significantly different from Homebound Alone. ${ }^{\mathrm{d}}$ Significantly different from Isolation/Homebound.

Abbreviations: SD, standard deviation; BMI, body mass index; TIDM/T2DM, type I/type 2 diabetes mellitus; HbAIc, hemoglobin Alc; GLP-I, glucagon-like peptide-I; TMIG-IC, Tokyo Metropolitan Institute of Gerontology Index of Competence.

and $15.6 \%$ and $32.9 \%$ in women, respectively. In the present study, which analyzed elderly diabetic patients receiving our hospital's outpatient care, the frequency of isolation and homeboundness was $37 \%$ and $13.3 \%$ in men and $28.9 \%$ and $20.6 \%$ in women, respectively, showing a higher tendency of isolation compared with homeboundness in both sexes. Although it is unclear why there were differences in the rates of isolation and homeboundness in our study compared with that of Fujiwara et al, ${ }^{15}$ there are some possible explanations. First, patients in our study were diabetic patients with high rates of insulin therapy; thus, it is possible that they tend to avoid interactions with others. That is, diabetic patients taking insulin tend to prefer hiding their insulin use from others' knowledge or to avoid activities with others altogether. ${ }^{23,24}$ Furthermore, it has been reported that diabetic patients tend to hesitate sharing meals with others because they need to adhere to a diet therapy. ${ }^{23,24}$ It is plausible that self-stigmas (ie, negative opinions about oneself or agreement to others' negative emotional reactions or opinions about them) held by diabetics in relation to their disease or necessary treatment are distancing them from others. ${ }^{23,24}$ Second, diabetic patients have higher incidences of comorbidities such as vascular complications, depression, and cognitive impairment than non-diabetics. ${ }^{16,17}$ These comorbidities may become additional factors that prevent them from interacting with others, thereby worsening their isolation. After excluding the neither isolated nor homebound group of the four categories of isolation and homeboundness, isolation was the most common of the remaining three categories for both sexes. That is, "outings without social interactions" are frequent in both male and female elderly diabetic patients in outpatient care. Therefore, increased awareness and prudence on the subject of isolation in elderly diabetic patients is warranted regardless of how often they leave the home. However, according to the investigation of sex differences in the frequency of isolation and homeboundness in this study, the incidence of isolation was higher in men than in women, whereas the incidence of homeboundness was higher in women than in 
Table 3 Multiple Regression with Higher-Level Functional Capacity as the Outcome

\begin{tabular}{|c|c|c|c|c|}
\hline & \multicolumn{2}{|l|}{ Unadjusted } & \multicolumn{2}{|l|}{ Adjusted } \\
\hline & Coefficient $(95 \% \mathrm{Cl})$ & $p$ & Coefficient $(95 \% \mathrm{Cl})$ & $p$ \\
\hline \multicolumn{5}{|l|}{ Men } \\
\hline Age, per year increase & & & $-0.01(-0.07$ to 0.05$)$ & 0.778 \\
\hline $\mathrm{HbAlc}$, per $1 \%$ increase & & & $0.05(-0.25$ to 0.35$)$ & 0.726 \\
\hline Living alone (vs no) & & & $0.40(-0.54$ to 1.34$)$ & 0.401 \\
\hline Depression (vs no) & & & $-1.41(-2.09$ to -0.73$)$ & $<0.001 *$ \\
\hline Cognitive impairment (vs no) & & & $-0.86(-1.61$ to -0.12$)$ & $0.023^{*}$ \\
\hline Sarcopenia (vs no) & & & $-1.62(-2.59$ to -0.64$)$ & $0.00 I^{*}$ \\
\hline Numbers of comorbidity, per I increase & & & $-0.05(-0.32$ to 0.22$)$ & 0.696 \\
\hline Non-isolation/Non-homebound & Ref & Ref & Ref & Ref \\
\hline Isolation Alone & $-1.38(-2.05$ to -0.72$)$ & $<0.00 I^{*}$ & $-0.94(-1.68$ to -0.21$)$ & $0.012^{*}$ \\
\hline Homebound Alone & $-2.16(-3.67$ to -0.66$)$ & $0.005^{*}$ & $-0.27(-1.93$ to 1.39$)$ & 0.746 \\
\hline Isolation/Homebound & $-4.93(-5.94$ to -3.92$)$ & $<0.00 I^{*}$ & $-4.03(-5.37$ to -2.68$)$ & $<0.001 *$ \\
\hline \multicolumn{5}{|l|}{ Women } \\
\hline Age, per year increase & & & $-0.10(-0.2$ to 0.0$)$ & $0.047^{*}$ \\
\hline $\mathrm{HbAlc}$, per $\mathrm{I} \%$ increase & & & $0.19(-0.39$ to 0.79$)$ & 0.506 \\
\hline Living alone (vs no) & & & $0.82(-0.52$ to 2.17$)$ & 0.228 \\
\hline Depression (vs no) & & & $-0.96(-2.25$ to 0.32$)$ & 0.142 \\
\hline Cognitive impairment (vs no) & & & $0.26(-1.08$ to 1.62$)$ & 0.696 \\
\hline Sarcopenia (vs no) & & & $-0.59(-2.05$ to 0.87$)$ & 0.426 \\
\hline Numbers of comorbidity, per I increase & & & $-0.25(-0.67$ to 0.17$)$ & 0.243 \\
\hline Non-isolation/Non-homebound & Ref & Ref & Ref & Ref \\
\hline Isolation Alone & $-1.46(-2.44$ to -0.48$)$ & $0.004^{*}$ & $-1.33(-2.93$ to 0.25$)$ & 0.099 \\
\hline Homebound Alone & $-1.58(-2.82$ to -0.33$)$ & $0.013^{*}$ & $-0.65(-2.56$ to 1.26$)$ & 0.501 \\
\hline Isolation/Homebound & $-3.88(-5.12$ to -2.63$)$ & $<0.00 I^{*}$ & $-3.01(-4.92$ to -1.1$)$ & $0.002 *$ \\
\hline
\end{tabular}

Note: ${ }^{*} \mathrm{P}<0.05$.

Abbreviations: $\mathrm{HbAlc}$, hemoglobin $\mathrm{Alc}$; $\mathrm{Cl}$, confidence interval.

men. The authors of a previous study reported that compared to women, men tended to deal with their health problems on their own or reject others' support ${ }^{25}$ and reasoned that this may have contributed to the higher rates of social isolation among men than among women. Furthermore, although the incidence of homeboundness in women is reported to be lower than that of men in a previous study, similar to what we observed, ${ }^{26}$ the reason for this is not known, warranting further investigation.

Fujiwara et $\mathrm{al}^{15}$ showed that isolation in men and homeboundness in women were significantly associated with future decline in high-level functional capacity. In our study, isolation in men and isolation+homeboundness in men and women were significantly associated with decline in high-level functional capacity. It has been previously reported that isolation in men is a stronger causal factor of decline in high-level functional capacity than in women, ${ }^{25}$ and this was consistent in our study as well. However, our results deviated from Fujiwara et $\mathrm{al}^{15}$ in terms of women. While Fujiwara et al noted no association between homeboundness and decline in high-level functional capacity, we found isolation to be more strongly associated with decline in high-level functional capacity than homeboundness, albeit not to statistically significant levels. In our study, we found a significant relationship between isolation+homeboundness and decline in highlevel functional capacity in both men and women. Mean TMIG-IC scores of isolated+homebound men and women were 6.8 and 8.0 points, respectively, showing markedly lower scores than the other groups. Although a previous study ${ }^{11}$ has reported a significant relationship between homeboundness and decline in high-level functional capacity, this relationship was not observed in our study in either sex. This suggests a synergistic effect of homeboundness and isolation in elderly diabetic patients who have an extremely large impact on decline in high-level functional capacity, suggesting that this group requires the highest level of precautions.

The following theorizes the mechanisms underlying the relationship between isolation and decline in high-level 
functional capacity. Interactions with others are reported to promote adaptive behaviors, improve endocrine responses to stress, ${ }^{27}$ prevent decline of cognitive function, and stabilize mental state. ${ }^{27}$ Furthermore, interactions with others are also reported to promote access to healthrelated information, and they may also be linked to healthpromoting behaviors. $^{28}$ Conversely, scarce interactions with others may inhibit endocrine responses, have negative effects of physical and mental states, and prevent healthpromoting behaviors, thereby contributing to decline in high-level functional capacity. In this study, isolation was associated with decline in high-level functional capacity in men only. Men tend to try to deal with health problems by themselves compared with women and tend to reject support from others. ${ }^{25}$ This tendency in men may also be the reason why isolation was linked with decline in high-level functional capacity in men only in this study.

To the best of our knowledge, the present study is the first to investigate isolation and homeboundness and their relationships with high-level functional capacity in elderly diabetic patients. Its strength also lies in having revealed that isolated individuals were common among male and female elderly diabetic patients and that the combination of isolation and homeboundness has an extremely high impact on decline in high-level functional capacity. In terms of clinical findings, we found that isolation and homeboundness are major problems in elderly diabetic patients and that identification of these factors may lead to early detection of decline in high-level functional capacity in this group. A previous study on communitydwelling elderly ${ }^{29,30}$ found that social participation can prevent decline in high-level functional capacity. Our results suggested the importance of further investigation on the effects of interventions for isolation and homeboundness in elderly diabetic patients, taking gender differences into account to examine how they influence high-level functional capacity outcomes.

There are several limitations to this study. First, the participants were outpatients of a department specializing in diabetes; therefore, patients with comparatively severe diabetes may be overrepresented. Thus, the results of this study should be applied to patients with mild diabetes or diabetes managed by a family physician with due caution. Second, adjustment for confounding factors may be inadequate. The fact that our analyses were not adjusted for factors such as educational attainment, income, and subjective assessment of health and well-being that were unexamined in this study may have affected study outcomes.
Third, many of the excluded patients had low TMIG scores and included many patients with physical and social frailty as suggested by their higher rates of depression and social isolation, which may have compromised the external validity of the present study. Fourth, there were not many men who were homebound but not isolated, which may have decreased the statistical power of our study, thereby influencing our results. Finally, this was a cross-sectional study, and it was thus difficult to make conclusive remarks on causal relationships. As such, future studies should examine isolation and homeboundness and their relationships with highlevel functional capacity in elderly diabetic patients in a longitudinal investigation to verify causal relationships.

\section{Conclusions}

To conclude, albeit, with some of the above-mentioned limitations, the present study focused on the frequency of isolation and homeboundness in elderly diabetic patients and verified their relationships with high-level functional capacity. This showed that the frequency of isolation was high in both men and women and that isolation in men and isolation+homeboundness in men and women were significantly associated with decline in high-level functional capacity. Thus, health professionals should care for isolated or isolated and homebound elderly diabetic patients with awareness of their increased vulnerability to decline in high-level functional capacity.

\section{Ethical Standards}

This study was approved by the Ethical Review Board of the Ise Red Cross Hospital and conducted in accordance with the Helsinki Declaration. Written informed consent was obtained from all participants before enrolment.

\section{Acknowledgments}

The authors would like to thank the staff members of the Department of Metabolic Diseases at the Ise Red Cross Hospital for their cooperation in this study. This study received no funding.

\section{Author Contributions}

SI carried out the design of the study and drafted the manuscript; KM worked on giving advice and reviewing from a medical point of view; RK, KI, KO, YS, KA, RF, and HT helped to draft the manuscript. All authors read and approved the final manuscript. All authors contributed to data analysis, drafting or revising the article, gave final 
approval of the version to be published, and agree to be accountable for all aspects of the work.

\section{Disclosure}

The authors report no conflicts of interest in this work.

\section{References}

1. Laan W, Bleijenberg N, Drubbel I, Numans ME, de Wit NJ, Schuurmans MJ. Factors associated with increasing functional decline in multimorbid independently living older people. Maturitas. 2013;75(3):276-281. doi:10.1016/j.maturitas.2013.04.005

2. Louie GH, Ward MM. Sex disparities in self-reported physical functioning: true differences, reporting bias, or incomplete adjustment for confounding? J Am Geriatr Soc. 2010;58(6):1117-1122. doi:10.1111/ j.1532-5415.2010.02858.x

3. Lawton MP, Brody EM. Assessment of older people: self-maintaining and instrumental activities of daily living. Gerontologist. 1969;9 (3):179-186. doi:10.1093/geront/9.3_Part_1.179

4. Kameyama K, Tsutou A, Fujino H. The relationship between health-related quality of life and higher-level functional capacity in elderly women with mild cognitive impairment. $J$ Phys Ther Sci. 2016;28(4):1312-1317. doi:10.1589/jpts.28.1312

5. Murakami K, Tsubota-Utsugi M, Satoh M, et al. Impaired higher-level functional capacity as a predictor of stroke in community-dwelling older adults: the Ohasama study. Stroke. 2016;47(2):323-328. doi:10.1161/STROKEAHA.115.011131

6. Taniguchi Y, Kitamura A, Nofuji Y, et al. Association of trajectories of higher-level functional capacity with mortality and medical and long-term care costs among community-dwelling older Japanese. J Gerontol a Biol Sci Med Sci. 2019;74(2):211-218. doi:10.1093/ gerona/gly024

7. Wong E, Backholer K, Gearon E, et al. Diabetes and risk of physical disability in adults: a systematic review and meta-analysis. Lancet Diabetes Endocrinol. 2013;1(2):106-114. doi:10.1016/S22138587(13)70046-9

8. Kuiper JS, Zuidersma M, Oude Voshaar RC, et al. Social relationships and risk of dementia: a systematic review and meta-analysis of longitudinal cohort studies. Ageing Res Rev. 2015;22:39-57. doi:10.1016/j.arr.2015.04.006

9. Saito M, Kondo K, Ojima T, Hirai H; JAGES group. Criteria for social isolation based on associations with health indicators among older people. A 10-year follow-up of the Aichi Gerontological Evaluation Study. Nihon Koshu Eisei Zasshi. 2015;62(3):95-105. doi:10.11236/jph.62.3_95

10. Hawton A, Green C, Dickens AP, et al. The impact of social isolation on the health status and health-related quality of life of older people. Qual Life Res. 2011;20(1):57-67. doi:10.1007/s11136-010-9717-2

11. Fujita K, Fujiwara Y, Chaves PH, Motohashi Y, Shinkai S. Frequency of going outdoors as a good predictors for incident disability of physical function as well as disability recovery in community-dwelling older adults in rural Japan. $J$ Epidemiol. 2006;16(6):261-270. doi:10.2188/jea.16.261

12. Ganguli M, Fox A, Gilby J, Belle S. Characteristics of rural homebound older adults: a community-based study. J Am Geriatr Soc. 1996;44(4):363-370. doi:10.1111/j.1532-5415.1996.tb06403.x

13. Dickens AP, Richards SH, Greaves CJ, Campbell JL. Interventions targeting social isolation in older people: a systematic review. $B M C$ Public Health. 2011;11:647. doi:10.1186/1471-2458-11-647

14. Ornstein KA, Leff B, Covinsky KE, et al. Epidemiology of the homebound population in the United States. JAMA Intern Med. 2015;175(7):1180-1186. doi:10.1001/jamainternmed.2015.1849
15. Fujiwara Y, Nishi M, Fukaya T, et al. Synergistic or independent impacts of low frequency of going outside the home and social isolation on functional decline: a 4-year prospective study of urban Japanese older adults. Geriatr Gerontol Int. 2017;17(3):500-508. doi:10.1111/ggi.12731

16. Sinclair AJ, Abdelhafiz A, Dunning T, et al. An international position statement on the management of frailty in diabetes mellitus: summary of recommendations 2017. J Frailty Aging. 2018;7(1):10-20. doi: $10.14283 /$ jfa.2017.39

17. Huxley R, Barzi F, Woodward M. Excess risk of fatal coronary heart disease associated with diabetes in men and women: meta-analysis of 37 prospective cohort studies. BMJ. 2006;332(7533):73-78. doi:10.1136/bmj.38678.389583.7C

18. Koyano W, Shibata H, Nakazato K, Haga H, Suyama Y. Measurement of competence: reliability and validity of the TMIG index of competence. Arch Gerontol Geriatr. 1991;13(2):103-116. doi:10.1016/0167-4943(91)90053-S

19. Seino Y, Nanjo K, Tajima N, et al. Report of the committee on classification and diagnostic criteria of diabetes mellitus. J Diabetes Investig. 2010;25:859-866.

20. Ida S, Murata K, Nakadachi D, et al. Development of a Japanese version of the SARC-F for diabetic patients: an examination of reliability and validity. Aging Clin Exp Res. 2017;29(5):935-942. doi:10.1007/s40520-016-0668-5

21. Hanyu H, Maezono M, Sakurai H, Kume K, Kanetaka H, Iwamoto T. Japanese version of the test your memory as a screening test in a Japanese memory clinic. Psychiatry Res. 2011;190(1):145-148. doi:10.1016/j.psychres.2011.04.025

22. Muramatsu K, Miyaoka H, Kamijima K, et al. The patient health questionnaire, Japanese version: validity according to the mini-international neuropsychiatric interview-plus. Psychol Rep. 2007;101(3 Pt 1):952-960. doi:10.2466/pr0.101.3.952-960

23. Uchigata Y. The still persistent stigma around diabetes: is there something we can do to make it disappear? Diabetol Int. 2018;9:209-211. doi:10.1007/s13340-018-0373-z

24. Kato A, Fujimaki Y, Fujimori S, et al. Psychological and behavioural patterns of stigma among patients with type 2 diabetes: a cross-sectional study. BMJ Open. 2017;7(3):e013425. doi:10.1136/ bmjopen-2016-013425

25. Kishi R, Horikawa N. Role of the social support network which influences age of death and physical function of elderly people: study of trends in and outside of Japan and future problems. Nihon Koshu Eisei Zasshi. 2004;51(2):79-93.

26. Negron-Blanco L, de Pedro-cuesta J, Almazan J, et al. Prevalence of and factors associated with homebound status among adults in urban and rural Spanish populations. BMC Public Health. 2016;16:574. doi:10.1186/s12889-016-3270-z

27. Cohen S, Gottlieb BH, Underwood LG. Social relation-ships and health. In: Cohen S, Underwood LG, Gottlieb BH, editors. Measuring and Intervening in Social Support. New York: Oxford University Press; 2000:3-25.

28. Sakurai R, Kawai H, Suzuki H, et al. Poor social network, not living alone, is associated with incidence of adverse health outcomes in older adults. J Am Med Dir Assoc. 2019;20(11):1438-1443. doi:10.1016/j.jamda.2019.02.021

29. Tomioka K, Kurumatani N, Saeki K, Chen K. The differential effects of type and frequency of social participation on IADL declines of older people. PLoS One. 2018;13(11):e0207426. doi:10.1371/journal. pone. 0207426

30. Tomioka K, Kurumatani N, Hosoi H. Association between social participation and 3-year change in instrumental activities of daily living in community-dwelling elderly adults. $J$ Am Geriatr Soc. 2017;65(1):107-113. doi:10.1111/jgs.14447 


\section{Publish your work in this journal}

Clinical Interventions in Aging is an international, peer-reviewed journal focusing on evidence-based reports on the value or lack thereof of treatments intended to prevent or delay the onset of maladaptive correlates of aging in human beings. This journal is indexed on PubMed Central, MedLine, CAS, Scopus and the Elsevie
Bibliographic databases. The manuscript management system is completely online and includes a very quick and fair peer-review system, which is all easy to use. Visit http://www.dovepress.com/ testimonials.php to read real quotes from published authors. 